\title{
Expression of miRNAs Associated with the AMLI-ETO, CBFB-MYHI, PML-RARA and AF9-MLL Oncoproteins in Acute Myeloid Leukemia
}

\begin{abstract}
Keywords: Acute myeloid leukemia; miRNAs; AML1-ETO; CBFBMYHI; PML-RARA; MLLT3-MLL

Abstract

MicroRNAs (miRNAs) are small noncoding RNAs of 18 25 nucleotides in length that regulate gene expression post transcriptionally. Moreover, recently miRNA have been implicated in both physiological responses, as well as having critical roles in acute myeloid leukemia. Interestingly, the miRNA expression profile in acute leukemia can discriminate between acute myeloid leukemia with common translocations and imply that the deregulation of specific miRNAs may play a role in the development of leukemia with these associated genetic rearrangements, also the extraordinary stability of miRNAs, makes it suitable to serve as diagnostic and prognostic biomarkers of acute myeloid leukemia. We will review the roles for miRNA here with emphasis on their function in human leukemia and the mechanisms of the AML1-ETO, CBFB-MYHI, PML-RARA and MLLT3 MLL oncoproteins on miRNAs expression in acute myeloid leukemia.
\end{abstract}

\section{Introduction}

Acute myeloid leukemia (AML) is a heterogeneous group of genetically diverse hematopoietic malignancies characterized by the accumulation of primitive myeloid cells arrested at early stages of differentiation and it also is the most common acute leukemia affecting adults, and its incidence increases with age [1-3]. AML has been observed with an incidence of 3.7 per 100,000 persons and an age-dependent mortality of 2.7 to nearly 18 per 100,000 persons [2].

Over the last 30 years, several specific chromosome aberrations have been described in AML [4]. Four major rearrangements in AML are the $\mathrm{t}(8 ; 21), \operatorname{inv}(16), \mathrm{t}(15 ; 17)$, and MLL/11q23 translocations, which account for $30 \%$ of all AML cases [5], and have been incorporated in the World Health Organization (WHO) classification as the criteria for sub classification of AML [6]. The $t(8 ; 21), t(15 ; 17)$, and inv(16) have been established as molecular indicators for favorable clinical outcome, whereas MLL-rearrangement is classified as a disease of intermediate or poor prognosis [1,7].

MicroRNAs (miRNAs) are small non-protein-coding RNAs that regulate gene expression at the posttranscriptional level and influence many aspects cellular such as proliferation, metabolism, and apoptosis, etc., they are central in contributing what type of cell a developing cell ultimately becomes [8]. It has been observed that the miRNAs are differentially expressed in hematopoietic tissues and to have an important role both in lineage differentiation and in human hematological malignancies [9-11].

\section{Journal of}

Human Anatomy \& Physiology

\author{
Jorge Organista-Nava ${ }^{1,2^{\star}}$, Yazmín Gómez-Gómez ${ }^{1,2}$, \\ Berenice Illades-Aguiar ${ }^{1}$ and Marco Antonio \\ Leyva-Vázquez $^{1^{*}}$ \\ ${ }^{\prime}$ Laboratory of Molecular Biomedicine, School of Chemical- \\ Biological Sciences, Guerrero State University, Mexico \\ ${ }^{2}$ Biomedical Sciences, Institute of Cellular Physiology, National \\ Autonomous University of Mexico (UNAM), University City, Mexico \\ *Address for Correspondence \\ Jorge Organista-Nava, Laboratory of Molecular Biomedicine, School of \\ Chemical-Biological Sciences, Guerrero State University, Av. Lázaro \\ Cárdenas S/N, Ciudad Universitaria, Chilpancingo, Guerrero, 39090, \\ México, E-mail: joorna@gmail.com \\ Marco Antonio Leyva-Vázquez, Laboratory of Molecular Biomedicine, \\ School of Chemical-Biological Sciences, Guerrero State University, Av. \\ Lázaro Cárdenas S/N, Ciudad Universitaria, Chilpancingo, Guerrero, \\ 39090, México, Tel: 52-747-471-0901; E-mail: leyvamarco13@gmail. \\ com \\ Submission: 07 September, 2015 \\ Accepted: 26 November, 2015 \\ Published: 08 December, 2015 \\ Copyright: () 2015 Organista-Nava J, et al. This is an open access \\ article distributed under the Creative Commons Attribution License, \\ which permits unrestricted use, distribution, and reproduction in any \\ medium, provided the original work is properly cited.
}

miRNA expression profiling studies have revealed marked differences in miRNA expression between cytogenetic subtypes of AML, including $\mathrm{t}(8,21)$, inv(16), and $\mathrm{t}(15,17)$, as well as those with less favourable-risk subtypes such as t(11q23)/MLL (mixed lineage leukemia) [12-16], so it has been suggested that the miRNAs are an important tool in molecular classification of the leukemia. In this review, we will summarize the association of the miRNAs expression with AML1-ETO, CBFB-MYH1, PML-RARA and MLLT3$M L L$ oncoproteins and discussed the mechanism of transcriptional activation and/or repression on miRNAs expression by these oncoproteins, with a specific focus on acute myeloblastic leukemia.

miRNAs Expression and Oncoproteins in AML

AML1-ETO; $\mathbf{t}(8 ; 21)(\mathbf{q} 22 ; \mathbf{q} 22)$

The acute myeloid leukemia (AML)-1 gene (also known as RUNX1) was identified as a target of chromosomal translocation in $\mathrm{t}(8 ; 21)$, which is associated with $\approx 15 \%$ of AML [17]. This translocation involves the AML1 gene on chromosome 21 and the ETO (MTG8) gene on chromosome 8, and generates an AML1-ETO fusion protein [18]. AML1 is able to form a hetero dimer with $\mathrm{CBF} \beta$ (PEBP2 $\beta$ ) and regulate the transcription of target genes by binding to the DNA sequence [19]. Moreover, it has been shown that AML1-ETO blocks the transactivation of various promoters, suggesting it may function as a negative regulator [20].

The microRNA dysregulation associated with AML1/ETO expressed in $\mathrm{t}(8 ; 21)$ have been observed [13,21-23] (Table 1). It was reported that AML1-ETO triggers the heterochromatic silencing 
Citation: Organista-Nava J, Gómez-Gómez Y, Illades-Aguiar B, Leyva-Vázquez MA. Expression of miRNAs Associated with the AML1-ETO, CBFB-MYH1, PML-RARA and AF9-MLL Oncoproteins in Acute Myeloid Leukemia. J Hum Anat Physiol 2015;1(1): 5.

ISSN: $2575-7563$

Table 1: miRNAs expression in rearrangements-positive AML

\begin{tabular}{|c|c|c|}
\hline miRNAs & Expression & Reference \\
\hline \multicolumn{3}{|l|}{ AML1-ETO-positive rearrangement } \\
\hline miR-9 & Downregulation & Emmrich et al. [22] \\
\hline $\begin{array}{l}\text { miR-18a, miR-19a-b, miR-20a, } \\
\text { miR-92, miR-193a and miR-196 }\end{array}$ & Downregulation & \multirow[t]{2}{*}{ Li et al. [13] } \\
\hline miR-126 and miR-130 & Upregulation & \\
\hline miR-223 & Downregulation & Fazi et al. [21] \\
\hline \multicolumn{3}{|l|}{ PML-RARA-positive rearrangement } \\
\hline Let7a and Let7d and miR-142 & Upregulation & \multirow{2}{*}{ Careccia et al. [33] } \\
\hline Let7c and miR107 & Downregulation & \\
\hline miR-16 and miR-181b & Upregulation & \multirow[b]{2}{*}{ Saumet et al. [32] } \\
\hline $\begin{array}{l}\text { miR-15b, miR143, miR-210, miR- } \\
223 \text { and miR-342 }\end{array}$ & Downregulation & \\
\hline \multicolumn{3}{|l|}{ MLL-AF9-positiverearrangement } \\
\hline $\begin{array}{l}\text { miR-22, miR-24, miR-29a, miR- } \\
\text { 29b, miR30a, miR-124, miR132, } \\
\text { miR-133a, miR-133b, miR-146a, } \\
\text { miR-146b, miR-155, miR-193b, } \\
\text { miR-221, miR-222, miR-424, miR- } \\
503 \text { and miR-542 }\end{array}$ & \multirow[t]{2}{*}{ Downregulation } & Forrest et al. [47] \\
\hline miR-150 & & Bousquet et al. [48] \\
\hline
\end{tabular}

of miR-193a and miR-223 by epigenetic silencing through of the binding at AML1-bindingsites and recruiting chromatin-remodeling enzymes [21,23]. miR-193a contribute to $t(8 ; 21)$ leukemogenesis by activating the PI3K signal pathway, Li, et al. observed that miR-193a and PTEN inhibition by AML1-ETO is the major pathway through which AML1-ETO mediates cell-cycle int(8;21) AML (Figure 1) [23].

On the other hand, it was reported that miR-223 is a direct transcriptional target of AML1-ETO, by recruiting chromatin remodeling enzymes at an AML1-binding site on the miR-223 gene, so AML1-ETO induces heterochromatic silencing of miR-223, also was observed that de-methylating treatment is able to restore functional endogenous mature miR-223, and induced granulocytic maturation of the cells by the increased expression levels of the myeloid differentiation marker CD11b (Figure 1) [21].

\section{CBFB-MYH11; Inv(16)(p13.1q22)}

The inv(16)(p13q22) rearrangement is present in approximately $10 \%$ of cases with de novo acute myeloid leukemia (AML) [24]. This chromosomal rearrangement results in the fusion of $C B F B$ and MYH11 genes (CBFB-MYH11 gene fusion) [25]. Patients with this fusion gene define a specific subgroup with a relatively good prognosis [24]. CBF beta normally interacts with RUNX1 to form a transcriptionally active nuclear complex and it was observed that CBFB-MYH11 plays an important role in oncogenesis, particularly in the process of cell cycle and proliferation regulation [25].

It was found that $\mathrm{miR}-126 / \mathrm{miR}-126^{*}$ is up regulation in CBFBMYH11-positive AML [13]. Also was reported that the enforced expression of miR-126 and its star strand in AML cell lines inhibited the apoptotic potential and facilitated cell survival [13,26,27]. In addition to the elevated expression of miR-126/126* in CBF AMLs was associated with promoter demethylation, but not with amplification or mutation of the genomic locus (Figure 2) [13,26]. Therefore, miR$126 / 126^{*}$ is considered as oncogene to be involved in leukemogenesis of inv(16)/CBFB-MYH11-positive AML (Figure 2).

\section{PML-RARA; t(15;17)(q22;q12)}

The fusion transcript of $P M L-R A R A$ is detectable in approximately $10 \%$ of AML patients [28], and becomes a major player disturbing proper promyelocytic differentiation [29]. This chromosomal rearrangement results in the fusion of $P M L$ gene on chromosome $15 \mathrm{q} 21$, and RARA gene on chromosome 17q21, and to the formation of the resultant chimeric oncoprotein PML-RARA [30]. PML-RARA heterodimers act of a negative manner on RARA, and have higher affinity to CoR and HDAC than RARA-RXR, resulting in enhanced hyper-methylation of the DNA [31]. Thus, PML-RARA appears linked to transcriptional perturbation of miRNA genes and several miRNAs, which are down regulated in PML-RARA-positive AML (Table 1) [32,33].

It was reported that the miR-210, miR-23a/24-2, miR-342 and let- $7 \mathrm{c}$ are directly repressed by the PML-RARA oncoprotein in acute promyelocytic leukemia(APL) cells $[32,33]$ by epigenetic silencing through of the binding at RARA-binding sites and recruiting chromatin-remodeling enzymes, and this correlated with the recruitment of the co repressors around the retinoid acid response elements (RARE) of miR-342 and promoters together with a sharp decrease in lysine 9 trimethyl-histone $\mathrm{H} 3$ (H3K9me3) at the RARE site proximal to the transcription start site (Figure 3) [33]. Therefore, miR-210, miR-23a/24-2, miR-342 and let-7c family might have an important role in AML pathogenesis.

miR-107 is a target the transcription factor NFI-A [34], which participates with $\mathrm{C} / \mathrm{EBPa}$ in the suppression in the human granulopoietic lineage differentiation, and in the contribution of miR-223 to the NFI-A transcriptional regulation [35]. miR-342 is associated in the stimulate of granulocytic differentiation [36]. Interestingly, the target of miR-342 is MEIS1, MEIS1 is a member of the TALE family of homeodomain genes, which they are closely related with the normal hematopoiesis [37]. The importance of MEIS1 in human leukemogenesis was underscored by the finding that it was frequently up-regulated in AML and ALL samples $[38,39]$. Besides, it is known that let-7 family members are involved in differentiation and development, as well as in anti proliferative functions, by targeting the RAS oncogene and the non-histone DNA binding protein HMGA2 [40,41].

\section{AF9-MLL; t $(9 ; 11)(p 22 ; q 23)$}

The $\mathrm{t}(9 ; 11)$ that results in fusion of the MLL gene at $11 \mathrm{q} 23$ and the AF9 gene at 9p22. At the molecular level, $\mathrm{t}(9 ; 11)(\mathrm{p} 22 ; \mathrm{q} 23)$ have different fusion types resulting from various breakpoints within the $M L L$ and AF9 break point cluster regions. All fusion types cause expression of an aberrant chimeric mRNA consisting of a $5^{\prime}$-MLL portion and a 3'-AF9 portion [42-44]. Patients with $M L L$-rearranged AML are often associated with poor prognosis, and effective targeted therapies are not available $[45,46]$. Dysregulation of miRNAs has been frequently observed in AML, including those carrying MLLrearrangements (Table 1) $[13,47,48]$.

The microRNA miR-150, a critical regulator of hematopoiesis, it was observed a downregulation of miR-150 in MLL-AF9-leukemia, 
Citation: Organista-Nava J, Gómez-Gómez Y, Illades-Aguiar B, Leyva-Vázquez MA. Expression of miRNAs Associated with the AML1-ETO, CBFB-MYH1, PML-RARA and AF9-MLL Oncoproteins in Acute Myeloid Leukemia. J Hum Anat Physiol 2015;1(1): 5.

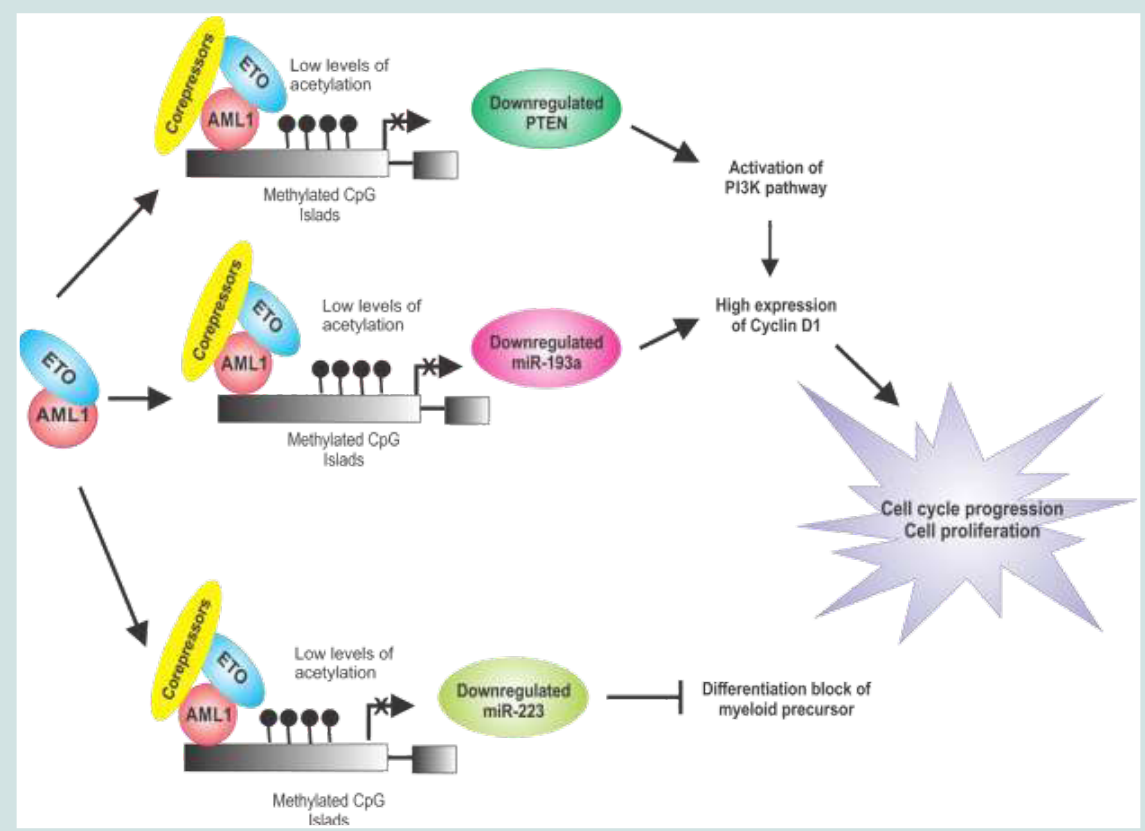

Figure 1: AML1/ETO oncoprotein in the regulation of PTEN, miR-193a and miR-223 and cellular processes affected in AML.

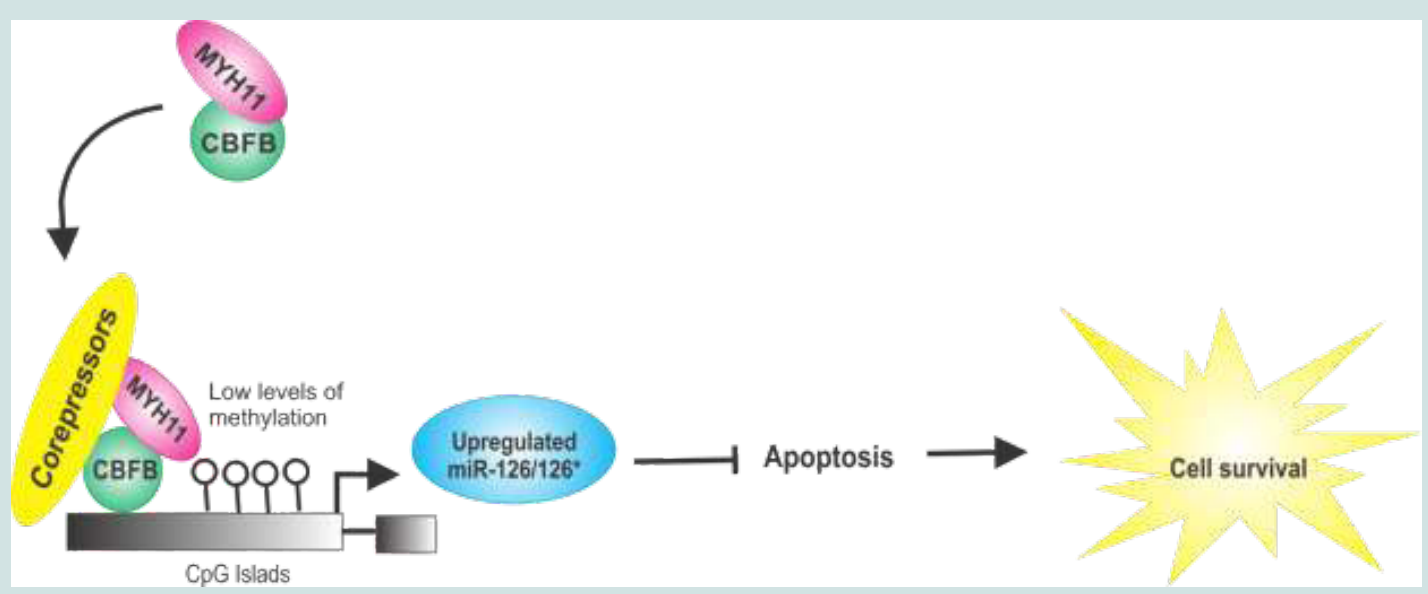

Figure 2: CBFB-MYH1 oncoprotein in the regulation of $\mathrm{miR} 126 / \mathrm{miR} 126^{*}$ and cellular processes affected in $\mathrm{AML}$.

besides that miR-150 down-regulates $M y b$ expression in large part by directly targeting its $3^{\prime}$-UTR [48]. Bcl-2, an anti-apoptotic protein known to be regulated by c-Myb, which it has been, reported up regulated in $M L L-A F 9$ leukemia [49]. The MLL-AF9 oncogene blocks apoptosis by inhibition of miR-150 and regulate the $M y b$ and $B c l 2$ expression in AML (Figure 4). Therefore, the miR-150dependent derepression of $M y b$, is an important contributor to the transformation process induced in MLL-AF9AML.

miR-424 and miR-503 are miRNAs that are repressed by the MLLAF9 leukemogenic fusion (Table 1) [47]. Both of these microRNAs directly target cell-cycle (and cell-cycle regulators. Likewise, it was observed that miR-424 and miR-503 down regulate the antidifferentiative miR-9 by targeting a site in its primary transcript (Figure 4), miR-9 was found up regulated in MLL-AF9-positive cells [47]. This data suggest the combined effects of multiple microRNAs and $M L L-A F 9$ oncogene in acute myeloid leukemia.

\section{Conclusions}

In summary, we have highlighted a broad network of miRNA expression in human acute myeloid leukemia. Some have oncogenic activity while others a have tumor suppressive role. miRNAs may be used as new molecular targets for the development of novel therapeutic strategies. Moreover, we could use the miRNAs expression profiling to inform the clinic on diagnosis and prognosis of the AML, or maybe allow for more targeted chemotherapy treatment.

\section{References}

1. Lowenberg B, Downing JR, Burnett A (1999) Acute myeloid leukemia. N Engl J Med 341: 1051-1062.

2. Deschler B, Lübbert M (2006) Acute myeloid leukemia: epidemiology and etiology. Cancer 107: 2099-2107. 
Citation: Organista-Nava J, Gómez-Gómez Y, Illades-Aguiar B, Leyva-Vázquez MA. Expression of miRNAs Associated with the AML1-ETO, CBFB-MYH1, PML-RARA and AF9-MLL Oncoproteins in Acute Myeloid Leukemia. J Hum Anat Physiol 2015;1(1): 5.

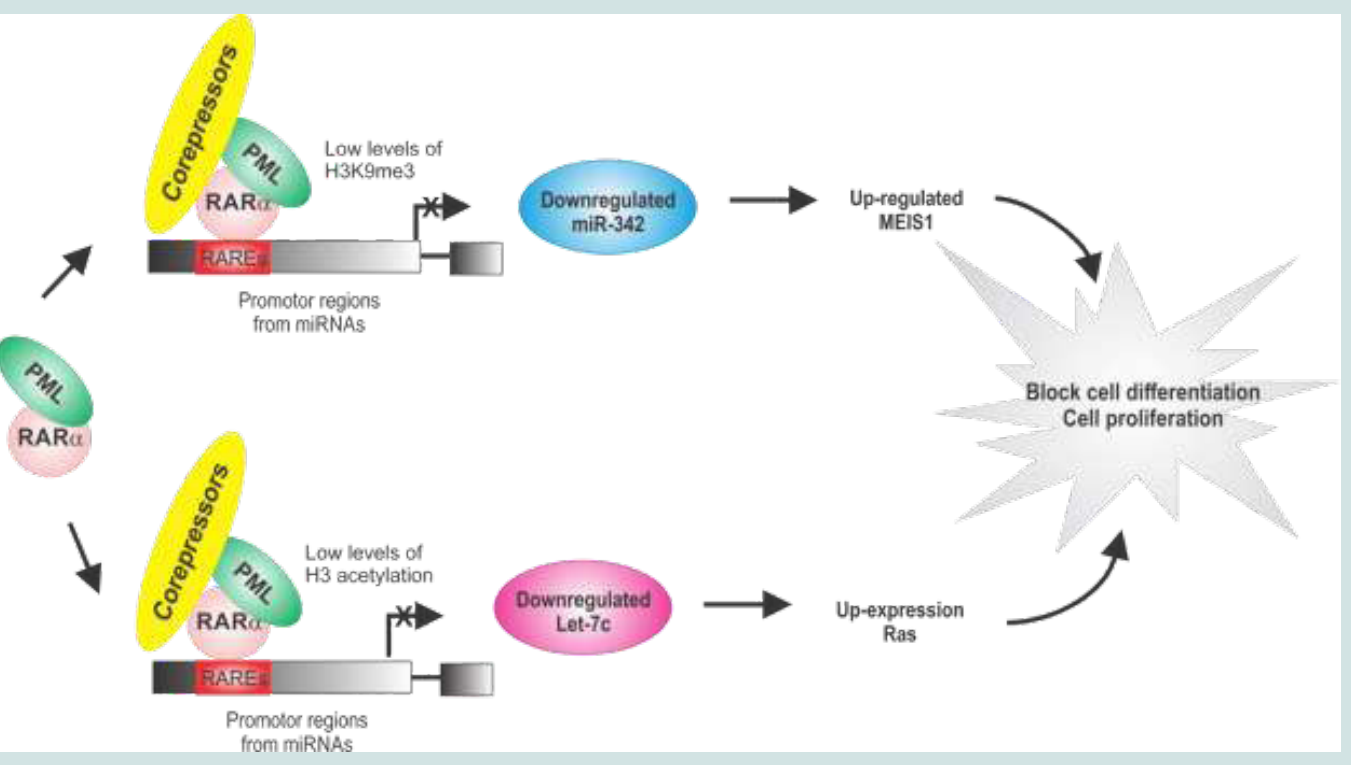

Figure 3: PML-RARA oncoprotein in the regulation of miR-342 and Let7c and cellular processes affected in AML.

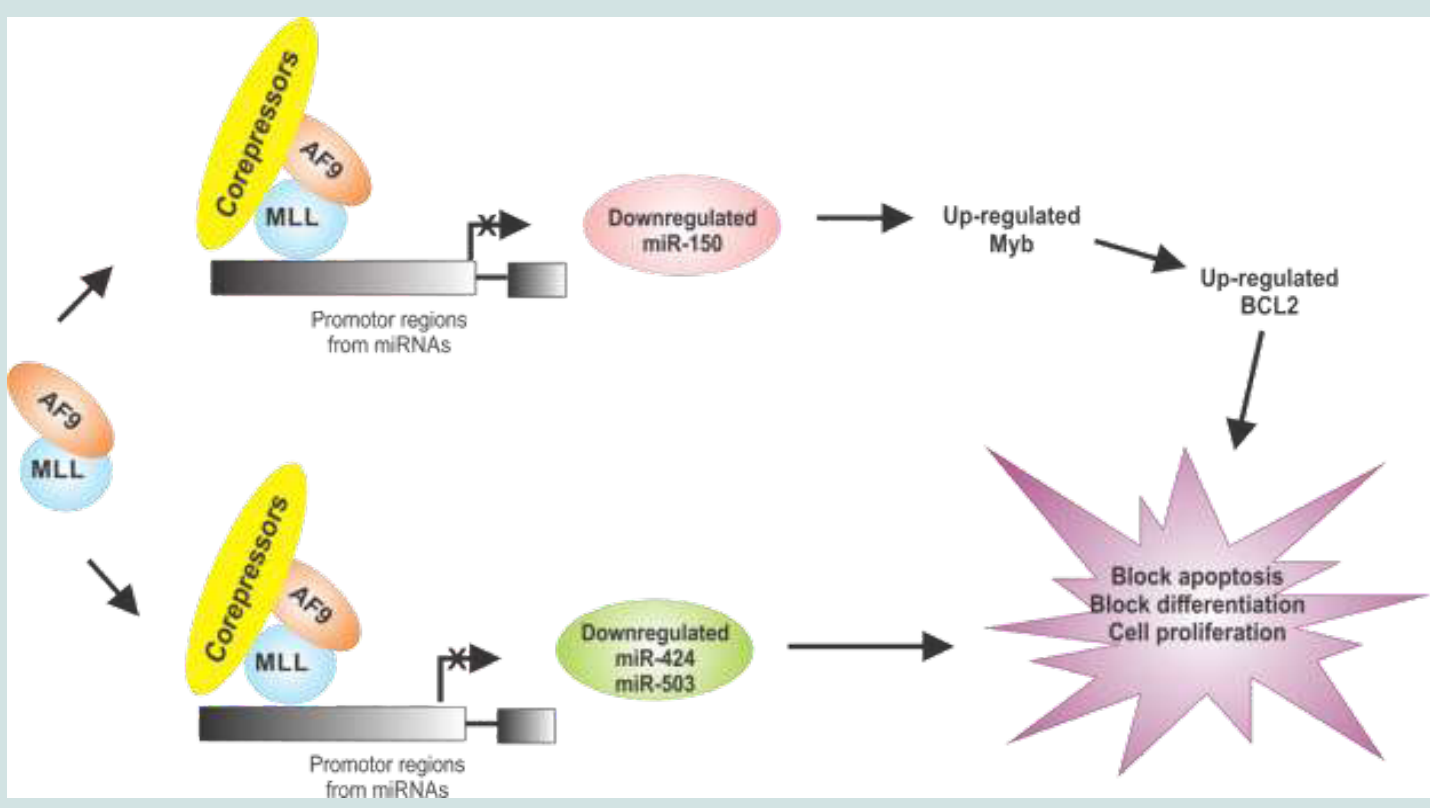

Figure 4: AF9-MLL oncoprotein in the regulation of miR-150, miR-424 and miR-503 and cellular processes affected in AML.

3. Song SJ, Pandolfi PP (2014) MicroRNAs in the pathogenesis of MDS and myeloid leukaemia. Curr Opin Hematol 21: 276-282.

4. Mrózek K, Heinonen K, Bloomfield CD (2001) Clinical importance of cytogenetics in acute myeloid leukaemia. Best Pract Res Clin Haematol 14: $19-47$.

5. Mitelman F, Johansson B, Mertens F (2007) The impact of translocations and gene fusions on cancer causation. Nat Rev Cancer 7: 233-245.

6. Steven H Swerdlow, International Agency for Research on Cancer, World Health Organization (2008) WHO classification of tumours of haematopoietic and lymphoid tissues, (4th Edn). International Government Publication, Lyon, France: International Agency for Research on Cancer, pp. 274-288.

7. Bullinger L, Valk PJ (2005) Gene expression profiling in acute myeloid leukemia. J Clin Oncol 23: 6296-6305.
8. Sun K, Lai EC (2013) Adult-specific functions of animal microRNAs. Nat Rev Genet 14: 535-548.

9. Fatica A, Fazi F (2013) MicroRNA-regulated pathways in hematological malignancies: how to avoid cells playing out of tune. Int J Mol Sci 14: 2093020953

10. Chen CZ, Li L, Lodish HF, Bartel DP (2004) MicroRNAs modulate hematopoietic lineage differentiation. Science 303: 83-86.

11. Fabbri M, Garzon R, Andreeff M, Kantarjian HM, Garcia-Manero G, et al (2008) MicroRNAs and noncoding RNAs in hematological malignancies: molecular, clinical and therapeutic implications. Leukemia 22: 1095-1105.

12. Jongen-Lavrencic M, Sun SM, Dijkstra MK, Valk PJ, Löwenberg B (2008) MicroRNA expression profiling in relation to the genetic heterogeneity of acute myeloid leukemia. Blood 111: 5078-5085. 
Citation: Organista-Nava J, Gómez-Gómez Y, Illades-Aguiar B, Leyva-Vázquez MA. Expression of miRNAs Associated with the AML1-ETO, CBFB-MYH1, PML-RARA and AF9-MLL Oncoproteins in Acute Myeloid Leukemia. J Hum Anat Physiol 2015;1(1): 5.

13. Li Z, Lu J, Sun M, Mi S, Zhang H, et al. (2008) Distinct microRNA expression profiles in acute myeloid leukemia with common translocations. Proc Natl Acad Sci U S A 105: 15535-15540.

14. Mi S, Lu J, Sun M, Li Z, Zhang H, et al. (2007) MicroRNA expression signatures accurately discriminate acute lymphoblastic leukemia from acute myeloid leukemia. Proc Natl Acad Sci U S A 104: 19971-19976.

15. Garzon R, Volinia S, Liu CG, Fernandez-Cymering C, Palumbo T, et al. (2008) MicroRNA signatures associated with cytogenetics and prognosis in acute myeloid leukemia. Blood 111: 3183-3189.

16. Popovic R, Riesbeck LE, Velu CS, Chaubey A, Zhang J, et al. (2009) Regulation of mir-196b by MLL and its overexpression by MLL fusions contributes to immortalization. Blood 113: 3314-3322.

17. Elagib KE, Goldfarb AN (2007) Oncogenic pathways of AML1-ETO in acute myeloid leukemia: multifaceted manipulation of marrow maturation. Cancer Lett 251: 179-186.

18. Downing JR, Higuchi M, Lenny N, Yeoh AE (2000) Alterations of the AML1 transcription factor in human leukemia. Semin Cell Dev Biol 11: 347-360.

19. Yuan Y, Zhou L, Miyamoto T, Iwasaki H, Harakawa N, et al. (2001) AML1ETO expression is directly involved in the development of acute myeloid leukemia in the presence of additional mutations. Proc Natl Acad Sci U S A 98: 10398-10403.

20. Martens JH, Stunnenberg HG (2010) The molecular signature of oncofusion proteins in acute myeloid leukemia. FEBS Lett 584: 2662-2669.

21. Fazi F, Racanicchi S, Zardo G, Starnes LM, Mancini M, et al. (2007) Epigenetic silencing of the myelopoiesis regulator microRNA-223 by the AML1/ETO oncoprotein. Cancer Cell 12: 457-466.

22. Emmrich S, Katsman-Kuipers JE, Henke K, Khatib ME, Jammal R, et al (2014) miR-9 is a tumor suppressor in pediatric AML with $t(8 ; 21)$. Leukemia 28: $1022-1032$

23. Li Y, Gao L, Luo X, Wang L, Gao X, et al. (2013) Epigenetic silencing of microRNA-193a contributes to leukemogenesis in $t(8 ; 21)$ acute myeloid leukemia by activating the PTEN/PI3K signal pathway. Blood 121: 499-509.

24. van der Reijden BA, Massop M, Tönnissen E, van de Locht L, Muus $P$, et al. (2003) Rapid identification of CBFB-MYH11-positive acute myeloid leukemia (AML) cases by one single MYH11 real-time RT-PCR. Blood 101: 5085-5086.

25. Shigesada K, van de Sluis B, Liu PP (2004) Mechanism of leukemogenesis by the inv(16) chimeric gene CBFB//PEBP2B-MHY11. Oncogene 23: $4297-$ 4307.

26. Li Z, Mi S, Lu J, Luo R, Sun M, et al. (2008) Cellular and Molecular BiologyClinical and Biological Implications of Aberrant Gene Expression: Poster Presentations - Proffered Abstracts: The role and functional mechanism of miR-126 in leukemogenesis. Cancer Res 68: 4239.

27. de Leeuw DC, Denkers F, Olthof MC, Rutten AP, Pouwels W, et al. (2014 Attenuation of microRNA-126 expression that drives CD34+38-stem/ progenitor cells in acute myeloid leukemia leads to tumor eradication. Cancer Res 74: 2094-2105.

28. Stone RM, Mayer RJ (1990) The unique aspects of acute promyelocytic leukemia. J Clin Oncol 8: 1913-1921.

29. Akagi T, Shih LY, Kato M, Kawamata N, Yamamoto G, et al. (2009) Hidden abnormalities and novel classification of $\mathrm{t}(15 ; 17)$ acute promyelocytic leukemia (APL) based on genomic alterations. Blood 113: 1741-1748.

30. Dong S, Geng JP, Tong JH, Wu Y, Cai JR, et al. (1993) Breakpoint clusters of the PML gene in acute promyelocytic leukemia: primary structure of the reciprocal products of the PML-RARA gene in a patient with $t(15 ; 17)$. Genes Chromosomes Cancer 6: 133-139.

31. Di Croce L, Raker VA, Corsaro M, Fazi F, Fanelli M, et al. (2002) Methyltransferase recruitment and DNA hypermethylation of target promoters by an oncogenic transcription factor. Science 295: 1079-1082.

32. Saumet A, Vetter G, Bouttier M, Portales-Casamar E, Wasserman WW, et al. (2009) Transcriptional repression of microRNA genes by PML-RARA increases expression of key cancer proteins in acute promyelocytic leukemia. Blood 113: 412-421.

33. Careccia S, Mainardi S, Pelosi A, Gurtner A, Diverio D, et al. (2009) A restricted signature of miRNAs distinguishes APL blasts from normal promyelocytes. Oncogene 28: 4034-4040.

34. Garzon R, Pichiorri F, Palumbo T, Visentini M, Aqeilan R, et al. (2007) MicroRNA gene expression during retinoic acid-induced differentiation of human acute promyelocytic leukemia. Oncogene 26: 4148-4157

35. Fazi F, Rosa A, Fatica A, Gelmetti V, De Marchis ML, et al. (2005) A Minicircuitry comprised of microRNA-223 and transcription factors NFI-A and C/EBPalpha regulates human granulopoiesis. Cell 123: 819-831.

36. De Marchis ML, Ballarino M, Salvatori B, Puzzolo MC, Bozzoni I, et al. (2009) A new molecular network comprising PU.1, interferon regulatory factor proteins and miR-342 stimulates ATRA-mediated granulocytic differentiation of acute promyelocytic leukemia cells. Leukemia 23: 856-862.

37. Diaz-Blanco E, Bruns I, Neumann F, Fischer JC, Graef T, et al. (2007) Molecular signature of $\mathrm{CD} 34(+)$ hematopoietic stem and progenitor cells of patients with CML in chronic phase. Leukemia 21: 494-504.

38. Rozovskaia T, Feinstein E, Mor O, Foa R, Blechman J, et al. (2001) Upregulation of Meis1 and HoxA9 in acute lymphocytic leukemias with the $\mathrm{t}(4:$ 11) abnormality. Oncogene 20: 874-878

39. Kumar AR, Li Q, Hudson WA, Chen W, Sam T, et al. (2009) A role for MEIS1 in MLL-fusion gene leukemia. Blood 113: 1756-1758.

40. Johnson SM, Grosshans H, Shingara J, Byrom M, Jarvis R, et al. (2005) RAS is regulated by the let-7 microRNA family. Cell 120: 635-647.

41. Peng Y, Laser J, Shi G, Mittal K, Melamed J, et al. (2008) Antiproliferative effects by Let-7 repression of high-mobility group A2 in uterine leiomyoma. Mol Cancer Res 6: 663-673.

42. Yamamoto K, Seto M, lida S, Komatsu H, Kamada N, et al. (1994) A reverse transcriptase-polymerase chain reaction detects heterogeneous chimeric mRNAs in leukemias with 11q23 abnormalities. Blood 83: 2912-2921.

43. Super HG, Strissel PL, Sobulo OM, Burian D, Reshmi SC, et al. (1997) Identification of complex genomic breakpoint junctions in the $\mathrm{t}(9 ; 11)$ MLL-AF9 fusion gene in acute leukemia. Genes Chromosomes Cancer 20: 185-195.

44. Langer T, Metzler M, Reinhardt D, Viehmann S, Borkhardt A, et al. (2003) Analysis of $\mathrm{t}(9 ; 11)$ chromosomal breakpoint sequences in childhood acute leukemia: almost identical MLL breakpoints in therapy-related AML after treatment without etoposides. Genes Chromosomes Cancer 36: 393-401.

45. Chen J, Odenike O, Rowley JD (2010) Leukaemogenesis: more than mutan genes. Nature Rev Cancer 10: 23-36.

46. Scholl C, Schlenk RF, Eiwen K, Döhner H, Fröhling S, et al. (2005) The prognostic value of MLL-AF9 detection in patients with $\mathrm{t}(9 ; 11)(\mathrm{p} 22 ; \mathrm{q} 23)$ positive acute myeloid leukemia. Haematologica 90: 1626-1634.

47. Forrest AR, Kanamori-Katayama M, Tomaru Y, Lassmann T, Ninomiya N et al. (2010) Induction of microRNAs, mir-155, mir-222, mir-424 and mir503 , promotes monocytic differentiation through combinatorial regulation. Leukemia 24: 460-466.

48. Bousquet M, Zhuang G, Meng C, Ying W, Cheruku PS, et al. (2013) miR150 Blocks MLL-AF9-associated leukemia through oncogene repression. Mol Cancer Res 11: 912-922.

49. Horton SJ, Jaques J, Woolthuis C, van Dijk J, Mesuraca M, et al. (2013) MLLAF9-mediated immortalization of human hematopoietic cells along different lineages changes during ontogeny. Leukemia 27: 1116-1126.v

\section{Acknowledgements}

J.O.N and Y.G.G. were recipients of fellowships from the Programa de Apoyo a los Estudios de Posgrado, Universidad Nacional Autónoma de México (PAEP-UNAM). 